\title{
GAMBARAN PERUBAHAN TEKANAN DARAH PADA PASIEN GAGAL GINJAL KRONIK YANG MENJALANI TERAPI HEMODIALISIS DI RUANG HEMODIALISA RUMAH SAKIT TK. II PELAMONIA MAKASSAR
}

\author{
Abdul Herman Syah Thalib \\ Akademi Keperawatan Makasar Jurusan Keperawatan
}

\begin{abstract}
Background: The kidneys have a very important role in maintaining a healthy body. The kidneys experience acute renal failure when the kidney cannot function suddenly. Without kidney replacement therapy, deaths from metabolic disorders can occur quickly. One kidney replacement therapy can be done is hemodialysis. Although hemodialysis is safe and beneficial for patients, it does not mean without side effects. Various complications can occur when patients undergo hemodialysis one of which is intradialisis hypertension. This complication can lead to new, more complex problems, including discomfort, increasing stress affecting the quality of life, worsening the patient's condition and even causing death. Objective To determine the description of blood pressure changes in patients with chronic renal failure undergoing hemodialysis therapy in the Hemodialysis room at TK II Pelamonia Hospital Makassar. Methods: This study used a descriptive survey method with a case study approach. Results: Research shows that patients undergoing hemodialysis therapy experience changes in blood pressure in pre and post hemodialysis. Conclusion: There is an effect of hemodialysis on changes in blood pressure in patients with kidney failure in the Hemodialysis Room of TK. II Pelamonia Hospital Makassar.
\end{abstract}

Keywords: Kidney Failure, Hemodialysis, Blood Pressure

\section{PENDAHULUAN}

Ginjal mempunyai peran yang sangat penting dalam menjaga kesehatan tubuh secara menyeluruh karena ginjal adalah salah satu organ vital dalam tubuh (Lemone, 2014). Ginjal dianggap mengalami kegagalan secara mendadak atau biasa disebut acute renal failure ketika ginjal tersebut tidak bisa berfungsi secara mendadak (Cahyaningsih, 2011). Gagal ginjal stadium akhir timbul akibat gangguan ginjal kronik yang progresif atau gagal ginjal yang akut yang gagal pulih. Tanpa terapi pengganti ginjal, kematian akibat kelainan metabolik dapat terjadi dengan cepat. Hemodialisis dipilih untuk mengatasi atau mencegah hiperkalemia yang mengancam jiwa (O'callaghan, 2009). Meskipun hemodialisis aman dan bermanfaat untuk pasien, namun bukan berarti tanpa efek samping. Berbagai komplikasi dapat terjadi saat pasien menjalani hemodialisis. Komplikasi intradialisis merupakan kondisi abnormal yang terjadi saat pasien menjalani hemodialisis. Komplikasi intradialisis yang umum dialami pasien antara lain frekuensi hipotensi intra dialisis terjadi pada 20-30 \% dialisis. Komplikasi lainnya yang dapat terjadi selama pasien menjalani hemodialisis adalah hipertensi intradialisis (Daugirdas, Blake, \& Ing, 2009). Komplikasi ini dapat 
mengakibatkan timbulnya masalah baru yang lebih kompleks antara lain ketidaknyamanan, meningkatkan stress dan mempengaruhi kualitas hidup memperburuk kondisi pasien bahkan menimbulkan kematian (Jablonski, 2007).

Menurut World Health Organization (WHO) tahun 2015 dan Global Burden of Desease (GDB), penyakit ginjal menyebabkan kematian sebanyak 163.275 orang setiap tahunnya. Penelitian yang dilakukan oleh (Rahmawati, 2016) menyatakan bahwa gangguan kardiovaskuler merupakan faktor risiko akibat penyakit gagal ginjal kronik, diperkirakan 10-30 kali lebih tinggi pada klien hemodialisis dari pada populasi umum. Peningkatan jumlah pasien dengan penyakit ginjal kronik diikuti dampak dari penyakit yang mempengaruhi kualitas hidup pasien sehingga kebutuhan dasarnya mengalami gangguan (Yuliaw, 2011).

Data dari Depkes Provinsi Sulawesi Selatan menyebutkan bahwa sepanjang tahun 2009 terdapat 461 kasus baru penyakit gagal ginjal kronik yang terbagi atas beberapa kabupaten khususnya kota Makassar yang mencapai 175 kasus (Riskesdas, 2013).

Tujuan penelitian untuk mengetahui gambaran tindakan hemodialisis terhadap perubahan tekanan darah pada pasien gagal ginjal kronik di Rumah Sakit Tk II Pelamonia Makassar.

\section{METODE PENELITIAN}

Metode yang digunakan dalam penelitian ini adalah survey deskriptif dengan menggunakan metode pendekatan studi kasus dengan tujuan untuk mendapatkan gambaran tindakan hemodialisis terhadap perubahan tekanan darah pada pasien gagal ginjal kronik.
Subjek dalam penelitian ini adalah dua pasien dewasa yang mengalami penyakit gagal ginjal kronik dengan kriteria subjek yaitu :

Kriteria inklusi :

a. Umur 35 - 50 thn.

b. Pasien yang kooperatif

c. Bersedia menjadi subjek studi kasus.

d. Pasien stadium 4

Kriteria eksklusi :

Pasien yang tidak bersedia menjadi subjek studi kasus.

Penelitian studi kasus ini akan dilakukan di Rumah Sakit Tingkat II Pelamonia Makassar di ruangan hemodialisis pada tanggal 12-19 Juli 2018. Pengumpulan data dilakukan dengan 2 cara yaitu :

a. Wawancara

Wawancara dilakukan untuk mengetahui identitas klien, keluhan utama, riwayat penyakit sekarang, riwayat penyakit dahulu, riwayat keluarga yang diperoleh baik dari klien, keluarga dan perawat.

b. Observasi

Pada penelitian ini menggunakan lembar observasi tekanan darah berupa lembar ceklist pada pasien gagal ginjal kronik.

Sedangkan untuk penyajian data dilakukan dengan tabel dan teks naratif.

\section{HASIL PENELITIAN \\ Gambaran Subjek Studi Kasus}

Dalam studi kasus ini dipilih 2 orang pasien sebagai subjek studi kasus yaitu subjek I (Ny.N) dan subjek II (Ny. $\mathrm{H})$. Kedua subjek tersebut sudah sesuai dengan kriteria yang ditetapkan.

1. Subjek I
a. Inisial
: Ny. N
b. Umur
: 38 Tahun
c. No. RM
: 401619 
d. Tgl Hemodialisis : 12 Juli 2018

e. Tgl Penelitian : 12 Juli 2018

2. Subjek II
a. Inisial
: Ny. H
b. Umur
: 38 Tahun
c. No. RM
: 160391
d. Tgl Hemodialisis : 12 Juli 2018
e. Tgl Penelitian : 12 Juli 2018

3. Pemaparan Fokus Studi

Tabel 1. Observasi Tekanan Darah

Subjek I

Hari/Tanggal : Hari Pertama/Kamis 12 Juli 2018

\begin{tabular}{cccc}
\hline Sesi & \multirow{2}{*}{ Jam } & \multicolumn{2}{c}{ Tekanan Darah } \\
\cline { 3 - 4 } Hemodialisis & & Sistole & Diastole \\
\hline Pre HD & $08: 05$ & 190 & 100 \\
& $08: 15$ & 180 & 100 \\
& $09: 15$ & 180 & 100 \\
Intra HD & $10: 15$ & 190 & 100 \\
& $11: 15$ & 200 & 100 \\
& $12: 15$ & 200 & 100 \\
Post HD & $12: 30$ & 200 & 100
\end{tabular}

Tabel 2. Observasi Tekanan Darah

Subjek I

Hari/Tanggal : Hari Kedua/ Senin 16 Juli 2018

\begin{tabular}{cccc}
\hline Sesi & \multirow{2}{*}{ Jam } & \multicolumn{2}{c}{ Tekanan Darah } \\
\cline { 3 - 4 } Hemodialisis & & Sistole & Diastole \\
\hline Pre HD & $08: 10$ & 180 & 110 \\
& $08: 20$ & 190 & 100 \\
& $09: 20$ & 180 & 110 \\
Intra HD & $10: 20$ & 200 & 100 \\
& $11: 20$ & 190 & 100 \\
& $12: 20$ & 190 & 100 \\
Post HD & $12: 30$ & 200 & 100 \\
\hline
\end{tabular}

Tabel 3. Observasi Tekanan Darah

Subjek I

Hari/Tanggal : Hari Ketiga/Kamis 19 Juli

2018

\begin{tabular}{cccc}
\hline \multirow{2}{*}{$\begin{array}{c}\text { Sesi } \\
\text { Hemodialisis }\end{array}$} & Jam & \multicolumn{2}{c}{ Tekanan Darah } \\
\cline { 3 - 4 } Pre HD & $08: 10$ & Sistole & Diastole \\
\hline & $08: 15$ & 190 & 90 \\
& $09: 15$ & 180 & 100 \\
Intra HD & $10: 15$ & 180 & 110 \\
& $11: 15$ & 190 & 110 \\
& $12: 15$ & 190 & 90 \\
Post HD & $12: 30$ & 200 & 100 \\
\hline
\end{tabular}

Tabel 4. Observasi Tekanan Darah Subjek II Hari/Tanggal : Hari Pertama/Kamis/12 Juli 2018

\begin{tabular}{|c|c|c|c|}
\hline \multirow{2}{*}{$\begin{array}{c}\text { Sesi } \\
\text { Hemodialisis }\end{array}$} & \multirow{2}{*}{ Jam } & \multicolumn{2}{|c|}{ Tekanan Darah } \\
\hline & & Sistole & Diastole \\
\hline \multirow[t]{3}{*}{ Pre HD } & 08:00 & 160 & 90 \\
\hline & $08: 10$ & 180 & 100 \\
\hline & 09:10 & 180 & 100 \\
\hline \multirow[t]{3}{*}{ Intra $H D$} & $10: 10$ & 180 & 90 \\
\hline & $11: 10$ & 190 & 90 \\
\hline & $12: 10$ & 200 & 100 \\
\hline Post HD & $12: 20$ & 190 & 100 \\
\hline
\end{tabular}

Tabel 5. Observasi Tekanan Darah Subjek II Hari/Tanggal : Hari Kedua/ Senin 16 Juli 2018

\begin{tabular}{cccc}
\hline \multirow{2}{*}{$\begin{array}{c}\text { Sesi } \\
\text { Hemodialisis }\end{array}$} & \multirow{2}{*}{ Jam } & \multicolumn{2}{c}{ Tekanan Darah } \\
\cline { 3 - 4 } & & Sistole & Diastole \\
\hline Pre HD & $07: 50$ & 180 & 100 \\
& $08: 00$ & 180 & 90 \\
& $09: 00$ & 190 & 90 \\
Intra $H D$ & $10: 00$ & 180 & 90 \\
& $11: 00$ & 180 & 100 \\
& $12: 00$ & 190 & 100 \\
Post $H D$ & $12: 15$ & 200 & 100 \\
\hline
\end{tabular}


Tabel 6. Observasi Tekanan Darah

Subjek II

Hari Tanggal : Hari Ketiga/Kamis 19 Juli 2018

\begin{tabular}{cccc}
\hline \multirow{2}{*}{$\begin{array}{c}\text { Sesi } \\
\text { Hemodialisis }\end{array}$} & \multirow{2}{*}{ Jam } & \multicolumn{2}{c}{ Tekanan Darah } \\
\cline { 3 - 4 } Pre HD & $08: 15$ & Sistole & Diastole \\
& $08: 00$ & 160 & 90 \\
& $09: 00$ & 190 & 100 \\
Intra HD & $10: 00$ & 180 & 90 \\
& $11: 00$ & 180 & 100 \\
& $12: 00$ & 190 & 100 \\
Post HD & $12: 20$ & 190 & 100 \\
\hline
\end{tabular}

\section{PEMBAHASAN}

Dari tabel observasi tekanan darah selama 4 jam terapi hemodialisis (pre, intra dan post hemodialisis) dapat dilihat bahwa kedua subjek tersebut mengalami perubahan tekanan darah. Dimana tekanan darah kedua subjek meningkat saat post hemodialisis. Tekanan darah merupakan gaya yang diberikan oleh darah terhadap setiap satuan luas dinding kapiler, dan diukur dalam millimeter air raksa (Arga, 2013). Menurut (Sherwood L, 2014), darah dipompa keseluruh tubuh oleh jantung dimana jantung menggunakan sistem pembuluh darah yang luas untuk memastikan darah menjangkau dari ujung kepala hingga ke ujung jari kaki. Darah mengalir keseluruh tubuh melalui pembuluh arteri dan vena. Tekanan darah merupakan tekanan yang didesakkan dengan mensirkulasikan darah pada dinding pembuluh darah, dan merupakan salah satu tanda-tanda vital yang prinsipil. Organ-organ yang ada dalam tubuh mengisi kembali nutrisi dan mengeluarkan zat-zat sisa metabolism dari darah menerima persentase curahan jantung yang lebih besar dari pada yang di perlukan untuk menenuhi kebutuhan metabolik. Darah tersebut mengalir dalam lengkung tertutup antara jantung dan jaringan. Arteri mengangkut darah dari jantung keseluruh tubuh dan vena mengembalikan darah dari jaringan kembali ke jantung. Dimana laju aliran darah melalui sebuah pembuluh berbanding lurus dengan gradien dan berbanding terbalik dengan resistensi. Hal ini menyatakan pentingnya tekanan darah yang stabil agar darah dapat mencapai tujuan (Sherwood L, 2014). Kestabilan tekanan darah merupakan salah satu faktor pada saat dilakukan tindakan hemodialisa. Menurut (Agarwal, R., and Weir, 2010). Tekanan darah dapat mempertahankan kestabilannya. Pengaturan jangka pendek tekanan darah dilakukan terutama oleh refleks baroreseptor. Pengaturan keseimbangan yang ada diginjal dipengaruhi hormon renin angiotensinaldosteron system (RAAS) dikarenakan hormon ini bekerja di ginjal. Oleh karena itu, ginjal memainkan peranan penting dalam perubahan jangka panjang pada tekanan darah. Hormon-hormon tersebut bereaksi di ginjal untuk mengontrol jumlah sodium dan air yang dikeluarkan. Jika terlalu banyak air atau sodium yang tinggal di ginjal, jumlah cairan dalam darah yang disebut dengan volume darah akan meningkat. Hal ini juga berlaku sebaliknya, jika jumlah cairan yang tinggal di ginjal sedikit maka volume darah akan menurun dan mengakibatkan penurunan tekanan darah. Hal ini dapat terjadi jika ginjal sudah mengalami kerusakan.

Pada penelitian ini didapatkan hasil bahwa kedua pasien mengalami perubahan tekanan darah. Hal ini dapat disimpulkan bahwa ada pengaruh tindakan hemodialisis terhadap perubahan tekanan darah pada pasien gagal ginjal kronik. 
Penelitian ini sejalan dengan penelitian yang dilakukan (Sarifuddin, 2012), didapatkan ada hubungan tindakan hemodialisa dengan perubahan tekanan darah. Hal ini disebabkan perubahan tekanan darah pada seseorang dapat terjadi karena berbagai faktor salah satu contohnya adalah stress dan kenyataan dilapangan pada saaat dilakukan penelitian didapatkan ada beberapa sampel yang terlihat stress. Ansietas, takut, stres dan emosi mengakibatkan stimulasi simpatik, yang meningkatkan frekuensi darah, curah jantung dan tahanan vaskular perifer. Efek stimulasi simpatik meningkatkan tekanan. Hemodialisa akan dapat membantu penderita dengan mempermudah kerja ginjal. Mengekskresi zat-zat sisa, garam, dan cairan yang berlebih agar tidak terakumulasi dalam sirkulasi tubuh, beberapa zat kimia dalam kadar yang aman bagi tubuh. Selain itu, proses hemodialisa juga akan meregulasi tekanan darah pasien. Proses yang terjadi pada selama menjalani hemodialisis adalah proses difusi, osmosis, dan ultrafiltrasi. Kelebihan cairan dikeluarkan melalui proses osmosis yaitu dengan menciptkan gradient tekanan darah yang dapat ditingkatkan melalui penambahan tekanan hidrostatik (ultrafiltrasi) pada mesin dialysis sehingga tekanan dialysis tersebut digunakan sebagai kekuatan penghisap pada membaran dan memfasilitasi pengeluaran air (Smeltzer \& Bare, 2010).

\section{KESIMPULAN DAN SARAN}

Setelah dilakukan penelitian pada Ny. N dan Ny. H selama menjalani terapi hemodialisis selama 4 jam dapat dilihat bahwa kedua pasien tersebut mengalami perubahan tekanan darah, dimana keduanya mengalami peningkatan tekanan darah pada post hemodialisis. Hal ini menunjukkan bahwa terdapat pengaruh terapi hemodialisis terhadap perubahan tekanan darah pasien gagal ginjal kronik yang menjalani terapi hemodialisis.

\section{DAFTAR RUJUKAN}

Agarwal, R., and Weir, M. R. 2010. DryWeight: A Concept Revisyed in an Effort to Avoid Medication-Directed Approaches for Blood Pressure Control in Hemodialysis Patients.

Arga. 2013. Gambaran Tekanan Darah Berdasarkan Faktor Pemberat Hipertensi. Retrieved from http://repository.uinjkt.ac.id

Cahyaningsih. 2011. Panduan Praktis Perawatan Gagal Ginjal (2nd ed.). Jogjakarta: Mitra Cendikia Press.

Daugirdas, J. T., Blake, P. G., \& Ing, T. S. (2009). Handbook of dyalisis (4th ed.). Philadelphia: Lipincot William \& Wilkins.

Hudakk. 2010. Critical Care Nursing a Holistic Approach (6th ed.). Philadelpia: JB Lipincot Company.

Jablonski, A. 2007. The multidimensional cracteristics of smptoms rported by paients on hmodialysis. Nephrology Nursing Journal. 34 (1).29.

Lemone, P. 2014. Keperawatan Medikal Bedah (5th ed.). Jakarta: EGC.

Lolyta, R. 2011. Analisis Faktor yang Mempengaruhi Tekanan Darah Hemodialisis pada Klien Gagal Ginjal Kronik. Ejournal.stikestelogorejo.ac.id.

National Kidney Foundation. 2009. The Kidney Outcomes Quality Initiative of National Kidney Foundation (NKF). Retrieved from http://www.kidney.org/professionals/ KDOQI/guidelines.ckd

O'callaghan, C. 2009. At a Glance Sistem 
Ginjal, edisi kedua. Jakarta: Erlangga.

Rahmawati. 2016. Pengaruh Tindakan Hemodialisis Terhadap Perubahan Tekanan Darah pada Pasien Gagal Ginjal Kronik di Unit Hemodialisis RSUP Dr. Wahidin sudirohusodo Makassar.

Riskesdas. 2013. Badan Penelitian dan Pengembangan Kesehatan Kementerian RI tahun 2013.Diakses: 28 April 2018, dari http://www.depkes.go.id/resources/d ownload/general/Hasil\%20Riskesdas $\% 20$ 2013.pdf.

Sarifuddin. 2012. Hubungan Tindakan Hemodialisa Dengan Perubahan Tekanan Darah Pasien Pasca Hemodialisis di Ruang Hemodialisa RSUD DR . M . M . Pelangi Ilmu, 05 No 02 . Retrieved from http://ejurnal.ung.ac.id/index.php/JPI /article/view/1106

Sherwood L. 2014. Fisiologi Manusia Dari Sel Ke Sistem. Pembuluh Darah Dan Tekanan Darah. Jakarta: EGC.

Smeltzer, S. C. O., \& Bare, B. G. 2010. Brunner \& Suddarth's Textbook of Medical-Surgical Nursing (10th ed.). Philadelphia: Lippincott Williams \& Wilkins.

Suharyanto, T., \& Madjid, A.2009. Asuhan Keperawatan Pada Klien Dengan Gangguan Sistem Perkemihan. Jakarta: TIM.

Yuliaw.2011. Hubungan Tindakan Hemodialisa Dengan Perubahan Tekanan Darah Pasien Pasca Hemodialisis di Ruang Hemodialisa RSUD DR. M.M. Dunda Limboto. 